\title{
Site differences in the fatty acid composition of subcutaneous adipose tissue of obese women
}

\author{
By Ph. G. PITTET*, D. HALLIDAY AND P. E. BATEMAN \\ Department of Nutrition and Division of Anaesthesia, Medical Research Council, Clinical \\ Research Centre, Watford Road, Harrow, Middlesex
}

(Received 26 September 1978 - Accepted 23 February 1979)

\begin{abstract}
I. Adipose tissue samples were obtained by needle biopsy from three subcutaneous sites (thigh, abdomen and upper arm) in twenty-two obese women. The fatty acid composition was determined using gas-liquid chromatography and the results presented relate to eleven component fatty acids.

2. The fatty acid composition of adipose tissue obtained from the arm and abdomen was remarkably similar, with the exception of the levels of lauric acid.

3. The analyses showed that the majority of the saturated fatty acids were present in smaller proportions whilst the majority of unsaturated fatty acids were present in larger proportions in the thigh than in the two other sites. Highly significant inter-site differences were demonstrated for six of the major fatty acids and also for both the total amounts of saturated and unsaturated fatty acids and their ratios.

4. No marked differences in the fatty acid composition of adipose tissue from obese subjects were revealed during this study when compared with previously reported results obtained from 'normal-weight' subjects.
\end{abstract}

Although numerous studies have been carried out to elucidate the biochemical and metabolic pathways of adipose tissue, comparatively few have dealt with fatty acid (FA) composition of adipose tissue.

In the early I960s several workers in East and South Africa investigated the FA composition of adipose tissue from adults of different ethnic origins. MacLaren et al. (1962) showed that, with the exception of lauric and myristic acids, abdominal fat samples from three racial groups were very similar despite marked dietary differences. A similar conclusion was reached by Krut \& Bronte-Stewart (1964) who also showed no effect of age on depot fat composition of adults of three races, but higher ratios for monounsaturated : saturated $\mathrm{FA}$ in women than in men.

In I965, MacLaren and his co-workers (MacLaren et al. 1965), investigating the adipose tissue FA composition of prematures, infants and adults in Lebanon, found in four adults and one I2-year-old child that the amounts of palmitoleic acid were significantly lower and those of stearic acid higher, in fat obtained from deep sites compared to that from superficial sites. This finding was not confirmed in two studies made in England by Heffernan (1963) and Brook (1971). Several of these authors reported some inter-site differences between the proportion of one or two major FA in the adipose tissue of the leg and of the abdomen.

Adipose tissue FA composition has been investigated for its possible relationship to atherosclerosis and diabetes (Antonini et al. 1970), myocardial infarction (Kirkeby et al. I972) and coronary heart diseases (Lang et al. 1977).

The purpose of this investigation was to compare the FA composition of adipose tissue from three different subcutaneous sites (upper arm, thigh and abdomen) obtained from obese female subjects.

- For reprints; present address: Institute of Physiology, University of Lausanne, 7 Rue du Bugnon, Ior I Lausanne, Switzerland. 


\section{MATERIALS AND METHODS}

Subjects. Twenty-two obese women were studied. They ranged between the ages of I8-68 years (mean $\pm \mathrm{SE} 3 \mathrm{I} \cdot 3$ years $\pm 2 \cdot 8$ ) and weighed $62-\mathrm{I} 45 \mathrm{~kg}$ (mean $\pm \mathrm{SE} 99 \mathrm{~kg} \pm 5 \cdot 04$ ) which constituted $18.208 \%$ (mean \pm SE $78 . \mathrm{I} \% \pm 8.9$ ) excess of ideal weight (Documenta Geigy; scientific tables, 7 th edition, p. 717, 1972). The protocol was approved by the Northwick Park Hospital Ethical Committee.

Subcutaneous adipose tissue samples were obtained by percutaneous needle biopsy from the thigh, abdomen and upper arm.

Lipids were extracted according to the procedure of Folch et al. (1957) and the methyl esters of the fatty acids wero prepared using sodium methoxide and analysed by means of a gas-liquid chromatograph (Pye Unicam Ltd, series No. I04), using glass columns ( $3 \mathrm{~m} \times$

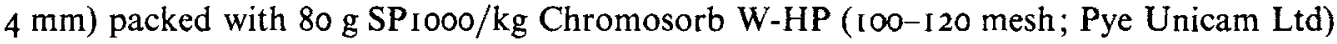
at $197^{\circ}$ with argon as carrier gas. The major fatty acid esters were identified by use of known lipid stabdards (Sigma Chemical Co. Ltd). Peak areas were quantitated by an automatic digital integrator (Pye Unicam Ltd, SP88 computing integrator). A number of the samples were also run on glass columns packed with $100 \mathrm{~g}$ polyethylene glycol adipate (PEG-A) $/ \mathrm{kg}$ I00-I 20 mesh Diatomite C-AW (Pye Unicam Ltd). Superior resolution and detection limits were obtained using the SPIOoo column and in view of its greater temperature stability (at $197^{\circ}$ ) this column was routinely used for the present study.

Statistical analysis was performed using Student's $t$ test for paired values.

\section{RESULTS}

Many different component FA were found under the conditions of the analysis employed though more than $95 \%$ of the total was made up of only seven acids: 12:0, 14:0, 16:0, I6: I, 18:0, 18: I, 18:2, Results of FA composition presented here include the eleven FA which were present in almost all samples. The amounts of these eleven FA found at three different sites from twenty-two obese women are presented in Table 1 . The combined amount of $14: 0,16: 0$ and $18: 0$ present in each site and that of $16: 1$ and $I 8: I$ and the ratios between them as well as the total amounts of saturated and unsaturated FA and the ratios between them are also presented in Table I. Of the component FA not presented here, the most frequently found were $8: 0,10: 0$ and $16: 2$. The values obtained from three sites in the same subject provided for a statistical analysis of the results, using a Student's $t$ test for paired values, to investigate possible inter-site differences. Such an analysis showed that there was no difference between the individual fatty acid levels in adipose tissue from the abdomen and from the arm except for lauric acid. However, it did reveal statistical differences between the levels of six major FA present in the thigh fat when compared to that from the abdomen or the arm.

The levels of $14: 0,16: 0$ and $18: 0$ were significantly higher and those of $16: 1,17: 1$ and I 8: $I$ lower in the arm and abdomen than in the thigh. For all other FA there was a general tendency for the saturated acids to be present in higher amounts and for the unsaturated acids to be present in lower amounts in the arm and abdomen than in the thigh. Examination of the partial and total sums of saturated and unsaturated FA as well as of their ratios confirmed that these inter-site differences were highly significant (Table I). 
Table I. Composition (mmol/mol) of the eleven major fatty acids of subcutaneous adipose tissue at three different sites in twenty-two obese women

(Mean values and standard deviations)

\begin{tabular}{|c|c|c|c|c|c|c|c|c|}
\hline \multirow[t]{2}{*}{ Fatty acids } & \multicolumn{2}{|c|}{ Arm } & & \multicolumn{2}{|c|}{ Thigh } & \multicolumn{2}{|c|}{ Abdominal wall } & \\
\hline & Mean & SD & & Mean & SD & Mean & SD & \\
\hline $12: 0$ & $6 \cdot 7$ & $2 \cdot 9$ & $b^{* *}$ & $6 \cdot 4$ & $2 \cdot 9$ & $8 \cdot 4$ & $3 \cdot 4$ & $a^{* * *}$ \\
\hline $14: 0$ & $50 \cdot \mathrm{I}$ & $10 \cdot 6$ & $\mathrm{a}^{* *}$ & $44 \cdot 7$ & $11 \cdot 7$ & 50.9 & $9 \cdot 6$ & $\mathrm{a}^{*}$ \\
\hline I5:0 & $5 \cdot \mathrm{I}$ & I. 4 & & $5^{\circ}$ & $1 \cdot 4$ & 49 & $I \cdot 4$ & \\
\hline $16: 0$ & $278 \cdot 0$ & $40 \cdot 0$ & $\mathrm{a}^{* * *}$ & $245 \cdot 5$ & $29 \cdot 3$ & $273 \cdot 2$ & $32 \cdot 4$ & $\mathrm{a}^{* * *}$ \\
\hline I6: I & $80 \cdot 3$ & $17 \cdot 7$ & $a^{* * *}$ & 107.8 & $21 \cdot 9$ & $82 \cdot 3$ & 23.9 & $\mathrm{a}^{* * *}$ \\
\hline $17: 0$ & 3.5 & $I \cdot I$ & & 30 & $1 \cdot 5$ & 3.5 & $I \cdot I$ & \\
\hline $17: 1$ & 43 & 0.9 & $a^{* *}$ & 5.1 & $1 \cdot 3$ & $4 \cdot 6$ & $I \cdot 6$ & $a^{* *}$ \\
\hline 18:0 & $50 \cdot 7$ & $12 \cdot 2$ & $a^{* * *}$ & $34 \cdot 1$ & $18 \cdot \mathrm{I}$ & $48 \cdot 3$ & 16.6 & $a^{* *}$ \\
\hline I 8: I & 464.8 & 19.7 & $a^{* * *}$ & 485.6 & $3 I^{1} \cdot 7$ & 465.5 & $20 \cdot 2$ & $a^{* * *}$ \\
\hline $18: 2$ & $48 \cdot 0$ & 30.9 & & 51.9 & 27.5 & 48.9 & 25.5 & \\
\hline $20: 1$ & $8 \cdot 4$ & $2 \cdot 4$ & & $9 \cdot 4$ & $3 \cdot 6$ & $9 \cdot 4$ & $4 \cdot 3$ & \\
\hline$I 4: 0+I 6: 0+I 8: 0$ & $378 \cdot 8$ & $48 \cdot 7$ & $a^{* * *}$ & $324 \cdot 3$ & $4 \mathrm{I} \cdot 9$ & $372 \cdot 4$ & $47 \cdot 3$ & $a^{* * *}$ \\
\hline $\begin{array}{l}\text { Total saturated } \\
16: 1+18: 1\end{array}$ & $\begin{array}{l}394 \cdot I \\
545 \cdot I\end{array}$ & $\begin{array}{l}5 \mathrm{I} \cdot 3 \\
22 \cdot 0\end{array}$ & $\begin{array}{l}a^{* * *} \\
a^{* * *}\end{array}$ & $\begin{array}{l}338.7 \\
593.4\end{array}$ & $\begin{array}{l}43 \cdot 4 \\
37 \cdot 0\end{array}$ & $\begin{array}{l}359 \cdot 2 \\
547 \cdot 8\end{array}$ & $\begin{array}{l}48 \cdot 4 \\
26 \cdot 5\end{array}$ & $\begin{array}{l}a^{* * *} \\
a^{* * *}\end{array}$ \\
\hline $\begin{array}{l}\text { Total unsaturated } \\
I 4: 0+I 6: 0+I 8: 0: I 6: I+I 8: I\end{array}$ & $\begin{array}{l}605 \cdot 8 \\
0.695\end{array}$ & $\begin{array}{l}47 \cdot 0 \\
0.110\end{array}$ & $\begin{array}{l}a^{* * *} \\
a^{* * *}\end{array}$ & $\begin{array}{l}659 \cdot 8 \\
0.547\end{array}$ & $\begin{array}{l}4 \mathrm{I} \cdot 5 \\
0 \cdot 100\end{array}$ & $\begin{array}{l}610 \cdot 7 \\
0.680\end{array}$ & $\begin{array}{l}46 \cdot 1 \\
0.116\end{array}$ & $\begin{array}{l}a^{* * *} \\
a^{* * * *}\end{array}$ \\
\hline Total saturated: total unsaturated & $0.65 \mathrm{r}$ & 0.128 & $a^{* * *}$ & 0.513 & 0.098 & 0.637 & 0.130 & 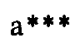 \\
\hline
\end{tabular}

a, Significantly different when compared to the thigh, using a $t$ test for paired values.

$\mathrm{b}$, Significantly different when compared to the waist, using a $t$ test for paired values.

${ }^{*} P<0.02,{ }^{* *} P<0.005,{ }^{* * *} P<0.001$.

\section{DISCUSSION}

The over-all picture of the FA composition of adipose tissue as well as the coefficients of variation of the different FA obtained in the present study, corresponded closely to results previously reported in the literature. The indication was, therefore, that the adipose tissue of our obese subjects had an FA composition that was grossly similar to that of a normal weight population of men, women and children, as presented in Table 2 . The same observation was established by Hirsch et al. (1960) although based on the results from a single obese subject. Krut \& Bronte-Stewart (I964) showed that there was no correlation between combined skinfold thickness and the FA ratio, I6:I + I8: I : I6:0+I8:0 in their female subjects.

The variations reported in the literature for the FA composition of adipose tissue, some of which are summarized in Table 2 , demonstrate differences possibly induced by diet (Hirsch et al. I960) and ambient temperature (MacLaren et al. 1962). The higher amount of I 6:o (second major component FA) found by MacLaren et al. (1962) (and other workers in Africa) when compared with values obtained from subjects resident in more temperate areas, can be explained by the need for a harder basic fat at a high ambient temperature. The amount of $16: \mathrm{I}$ in our subjects is of particular interest in that it was higher than other published values. This may be a reflexion of the obese state, as a similar result was presented by Hirsch et al. ( 1960 ) in their single obese female subject.

No difference could be demonstrated between the FA composition of adipose tissue from the abdomen and the arm, with the exception of lauric acid. However, statistical differences were demonstrated in the level of six major FA present in the thigh when compared with the levels in either the abdomen or the arm. This finding confirms and extends results obtained earlier by several workers (MacLaren et al. 1962; Heffernan, 1963; Brook, 1971) which were obtained for two or three major FA only (with the exception of the work of Brook, 197I) and 
Table 2. Comparison of adipose tissue fatty acid composition (weight \%) obtained in the present study with those obtained in earlier studies

(Mean values and standard deviations)

\begin{tabular}{|c|c|c|c|c|c|c|c|c|c|c|c|}
\hline \multirow{4}{*}{$\begin{array}{l}\text { Fatty } \\
\text { acids }\end{array}$} & \multicolumn{2}{|c|}{$\begin{array}{l}\text { Hirsch et al. } \\
\quad(1960)^{*}\end{array}$} & \multirow{4}{*}{ (2) } & \multirow{3}{*}{\multicolumn{2}{|c|}{$\begin{array}{c}\text { MacLaren et al. } \\
(1962) \dagger\end{array}$}} & \multirow{3}{*}{\multicolumn{2}{|c|}{$\begin{array}{l}\text { Heffernan } \\
\text { (I963) } \ddagger\end{array}$}} & \multirow{3}{*}{\multicolumn{2}{|c|}{$\begin{array}{r}\text { Brook } \\
(1971) \S\end{array}$}} & \multirow{2}{*}{\multicolumn{2}{|c|}{$\begin{array}{l}\text { Present } \\
\text { studyll }\end{array}$}} \\
\hline & \multirow{3}{*}{$\begin{array}{l}\text { Mean } \\
\text { (I) }\end{array}$} & \multirow{3}{*}{ SD } & & & & & & & & & \\
\hline & & & & & & & & & & & \\
\hline & & & & Mean & SD & Mean & SD & Mean & SD & Mean & SD \\
\hline $14: 0$ & $3 \cdot 3$ & 0.1 & $2 \cdot 8$ & $4 \cdot 6$ & $1 \cdot 6$ & $4 \cdot 2$ & 0.8 & $4 \cdot 8$ & $I \cdot 2$ & $4^{\prime} I$ & 0.9 \\
\hline 16:0 & 19.5 & $2 \cdot I$ & 23.0 & $3 I \cdot 3$ & 3.5 & 23.4 & $2 \cdot 7$ & 23.5 & $4 \cdot 3$ & $25 \cdot 3$ & 3.5 \\
\hline 16: I & 6.9 & 0.1 & 8.8 & 44 & $I \cdot 2$ & $7 \cdot 0$ & $1 \cdot 9$ & $7 \cdot 3$ & 3.5 & $8 \cdot 5$ & $2 \cdot 3$ \\
\hline 18:0 & $4 \cdot 2$ & $I \cdot I$ & 3.8 & $4 \cdot 5$ & $I \cdot I$ & 4.9 & $I \cdot 2$ & $6 \cdot 7$ & $2 \cdot 7$ & $4 \cdot 7$ & 1.8 \\
\hline I 8: 1 & $46 \cdot 7$ & 3.0 & $46 \cdot 9$ & $49 \cdot 0$ & 3.0 & $52 \cdot 8$ & 3.8 & $47 \cdot 8$ & $3 \cdot 6$ & 49.5 & $2 \cdot 7$ \\
\hline 18:2 & I I 4 & I. 4 & $12 \cdot 9$ & 5.6 & $I \cdot 0$ & $6 \cdot 9$ & $1 \cdot 8$ & $7 \cdot 7$ & $2 \cdot 4$ & $5 \cdot 2$ & 2.9 \\
\hline
\end{tabular}

* (I) Fat samples from unspecified origin (probably abdominal wall or buttock from twelve healthy young adults (five women and seven men). (2) One obese woman, 54 years, $114 \mathrm{~kg}$.

$\dagger$ Abdominal wall fat from ten Europeans established in East Africa.

\$ Average composition of tissue obtained from abdominal wall, buttock and leg (five subjects).

$\S$ Average composition of tissue obtained from lower leg (nineteen subjects, children and adults) and from other subcutaneous sites (sixty subjects, children and adults).

If Average composition of tissue obtained from abdominal wall, thigh and upper arm in each of twentytwo obese women.

when comparing lower leg to other sites (usually abdomen). The present study showed that there was a general tendency for nearly all unsaturated FA to be present in greater proportions in the thigh than in either the abdomen or the arm. This was clearly demonstrated by the significant differences in the total amount of saturated and unsaturated FA (and their ratios) presented in Table I. Such differences would make for a softer fat in the thigh (as well as in the leg, as reported by other authors) than in the abdominal wall and the upper arm, and, as suggested by MacLaren and his colleagues (MacLaren et al. 1962) and also by Henriques \& Hansen (I90I) with their work on depot fat in the pig, the increase in unsaturated FA at the expense of saturated FA is probably related to differences in ambient temperatures. Also, this is possibly coupled with an effect of the local body temperature at the site of the depot fat (Hilditch \& Williams, 1964).

Unpublished results from our laboratory obtained on a small group of obese patients, showed that a short-term weight-reducing regimen (3500 kJ/d during I month) induced a change in the relative proportion of saturated to unsaturated FA in favour of the latter, at three sites.

More work is desirable to examine whether the higher amount of palmitoleic acid found in obese subjects (in this study and in the case analysed by Hirsch and his colleagues) than in 'normal-weight' subjects is a true effect of obesity and also to investigate the effect of a long-term weight-reducing diet on the FA composition of adipose tissue at different sites in obese people.

\section{REFERENCES}

Antonini, F. M., Bucalossi, A., Petruzzi, E., Simoni, R., Morini, P. L. \& D'Allessandro, A. (1970). Atherosclerosis Ir, 279.

Brook, C. G. D. (1971). Br. J. Nutr. 25, 377.

Folch, J., Lees, M. \& Sloane-Stanley, H. (1957). J. biol. Chem. 22, 497.

Heffernan, A. G. A. (1963). Clin. Sci, 25, 423.

Henriques, V. \& Hansen, C. (1901). Skand. Arch. Physiol. I1, I5I.

Hilditch, T. P. \& Williams, P. N. (1964). In The Chemical Constitution of Natural Fats, 4 th ed. chapter III. London: Chapman \& Hall. 
Hirsch, J., Farquhar, J. W., Ahrens, E. H. Jr, Peterson, M. L. \& Stoffel, W. (1960). Am. J. Clin. Nutr. 8, 499. Kirkeby, K., Nitter-Hauge, S. \& Bjerkedal, I. (1972). Acta. Med. Scand. I9I, 32 I.

Krut, L. H. \& Bronte-Stewart, B. (1964). J. Lipid Res. 5, 343.

Lang, P. D., Degott, M. \& Vollmar, J. (1977). Atherosclerosis 26, 29.

MacLaren, D. S., Ajans, Z. A. \& Awdeh, Z. (1965). Am. J. Clin. Nutr. 17, 17 I.

MacLaren, D. S., Read, W. W. C. \& Chimbe, A. (1962). Clin. Sci. 23, 247. 